\title{
NATIONAL GHG EMISSIONS PROJECTIONS FROM INDUSTRIAL PROCESSES - METAL INDUSTRY
}

\author{
Iulia Mircea ${ }^{1,2, *}$, Mihaela Balanescu ${ }^{3}$ \\ 1"POLITEHNICA" UNIVERSITY OF TIMISOARA, Timisoara, \\ 300006, Romania \\ ${ }^{2}$ INSTITUTE FOR STUDIES AND POWER ENGINEERING, \\ Bucharest, 20371, Romania \\ ${ }^{3}$ Center for Research and Eco-Metallurgical Expertise, UNIVERSITY \\ POLITEHNICA OF BUCHAREST, Bucharest, 060042, Romania
} *iulia.bunda@ispe.ro

\begin{abstract}
The EU ETS is a policy tool used to promote investment in clean, low-carbon technologies and has placed climate change on the companies' agenda, by putting a price on carbon. The EU ETS cap and trade concept were the first policy tool used and implemented in the world for the greenhouse gas emissions (GHG). Metals process sector is the largest industrial source of greenhouse gases, with steel as the main culprit. Traditional methods of extracting iron from it or require a carbon-based reductant produce large quantities of $\mathrm{CO}_{2}$. The proposed methodology for achieving emission forecasts for GHG emissions is based on historical data from the National Emissions Inventory (NIGHGE) between 1989 - 2015, and, on the forecasts of macroeconomic indicators considered in the strategies of the Romanian Government and policies adopted for the economic and social development of the country. In the paper one analyzes the GHG emissions from industrial processes for Romanian for iron and steel sector and GHG emissions projections for this sector until 2035 will be presented. Keywords: iron and steel production, GHG emissions, projections
\end{abstract}

\section{Introduction}

In order to comply with all commitments assumed under the Kyoto Protocol, the European Union has introduced the emissions trading scheme for greenhouse gases (EU ETS), a mechanism based on commercial principles in order to encourage GHG emission reductions, in an effective technical and economic manner. The EU ETS scheme reduces costs to achieve specific targets, taking advantage of reducing the various incremental costs of the participants involved, with different emission sources. Purpose of the scheme is to contribute to the reduction of GHG emissions from the industrial activities listed in Annex I to the ETS Directive. The EU directives adopted so far establish a system for trading greenhouse gas emission allowances within the European Community. The measures to reduce GHG emissions and the process of adopting policies include periodic estimation of the projected effects associated with the measures or emissions projections at different time horizons.

GHG emission reduction targets will pay particular attention to the emission projections process in order to ensure a permanent process of assessing and adjusting policies and measures previously adopted to ultimately achieve the GHG emission level assumed [1].

It is estimated that emissions from industry sector represent over $30 \%$ of global GHG emissions in 2010, and are greater than emissions from either the buildings or transport end-use sectors [2]. Also, emissions from industry sector in 2010 are projected to increase by $50-150 \%$ till 2050 , unless energy efficiency 
deployment measures are not accelerated significantly [3].

\section{Industrial processes sector - metal industry}

Steel production is an emissions intensive process. CO2 emissions released by iron and steel industry represent an important part from the total amount of global emissions [4]. An adequate assessment of the $\mathrm{CO} 2$ emissions released at the national, sectorial or industrial plants level, gives the first indications for the localization and the amplitude of the actions route to be used, in order to control and to reduce these emissions. Also, to know the evolution of the emissions amounts in a certain period, such information could be obtained through the elaboration of adequate technical-economic forecasts The main technological flows generally available worldwide in manufacturing of steel products are:

- integrated route (BF-BOF) based on iron ore and coking coal used in blast furnaces, followed by oxygen steelworks and rolling mills;

- electric route (EAF) based on the use of scrap in electric arc furnaces, followed by rolling mills;

- "direct reduction" route, following the chain: iron ore used in reduction furnaces - electric steelworks - rolling mills.

The first flow is specific to large integrated factories, the last two being found in smaller factories. Currently, in Romania, steel production is based on the first two flow types presented above.

The iron and steel industry in Romania was initially developed based on local reserves of iron ore and coal. In the integrated factories, process flow structure underwent several changes over time. Maintaining the main stages of the flow (pig-iron production, steel making and rolling), changes were accomplished, mainly in intermediate stages.

Factories, and, in recent years, mini-mills, based on electric arc furnaces, were widely developed as Siemens Martin furnaces (BF-OH flow). They were decommissioned and the amount of available scrap increased. At the same time, relatively low cost of scrap used in electric arc furnace compared with the high cost of pig-iron used in Linz-Donawitz converters (BF-BOF flow) made the share of electric steel in steel production to increase.

Table 1 shows the main iron and steel producers in Romania and changes in the types of steelmaking processes.

Table 1. Overview of factories and steelmaking processes in Romania

\begin{tabular}{llll} 
Factory location & $\begin{array}{l}\text { Year } \\
\text { of } \\
\text { founda } \\
\text { tion }\end{array}$ & $\begin{array}{l}\text { Steelmaking route } \\
\text { Past (in } \\
\text { 1989) }\end{array}$ & Actual \\
\hline Galati & 1961 & BF - BOF & $\begin{array}{l}\text { BF- } \\
\text { BOF }\end{array}$ \\
Hunedoara & 1882 & BF- OH & EAF \\
Targoviste & 1973 & EAF & EAF \\
Campia Turzii & 1920 & EAF & EAF \\
Resita & 1771 & BF-OH & EAF \\
Otelu Rosu & 1796 & EAF & EAF \\
Calarasi & 1976 & EAF & EAF \\
\hline
\end{tabular}

$\mathrm{EAF}=$ Electric Arc Furnace; $\mathrm{BF}=$ Blast Furnace; $\mathrm{BOF}=$ Basic Oxygen Furnace; $\mathrm{OH}=$ Siemens Martin/Open Hearth Furnace

The main sectors that use steel are construction, with a share of around 38\%, followed by automotive industry (16\%) and mechanical engineering (14\%) [5].

Because on the BF-BOF route, the $\mathrm{CO} 2$ emissions per tonne of steel are much higher (around 5 times) than those resulted on EAF route, nationwide manufacturing structure significantly influences the emissions level.

The most important quantity of steel in Romania is made on BF-BOF route. It must be noted that the entire production of BOF steel are made in only one facility. Worldwide steel production has an exponential increase in last years. Thus, in 2001, world liquid steel production was $851,073 \mathrm{kt}$, and in 2015 reached a value of $1,620,408 \mathrm{kt}$, representing a increase with around $90 \%$ [6]. With concern to the weight of the steelmaking route, worldwide, in 2015, the BF-BOF steel weight was $74.2 \%$, the EAF steel represented $25.2 \%$, and the rest $(0.6 \%)$ was $\mathrm{OH}$ steel. In the same year in the EU-28 the BF-BOF steel represented $60.6 \%$, and the EAF steel was $39.4 \%$.

\section{Methodology}

GHG emission projection methodology is based on historical data from the National Greenhouse Gasses Emissions Inventory (NIGHGE), over 
the period 1989 - 2015 and on projected macroeconomic indicators, considered in the strategies of the Romanian Government, as well as policies adopted for the economic and social development of the country, in conjunction with the EU Directives.

Projections of GHG emissions are performed for three scenarios, specifically:

- a reference scenario "business as usual" (scenario without measure s- WOM) feasible in the future that does not include special activities to reduce GHG emissions;

- a reduction scenario that is similar to the reference scenario in terms of development of socio-economic indicators, but contains policies and measures to reduce GHG emissions (scenario with measures - WM);

- a reduction scenario with additional measures that is similar to the reduction scenario but contains additional measures to reduce GHG emissions (scenario with additional measures WAM)

The process of achieving the GHG emission projection and evaluation of alternatives to reduce them is particularly difficult, and therefore the authors based the research on special programs, which allow identification of sectors of low importance to GHG emissions, correlated with the socio-economic development of the country.

According to the IPCC 2006 methodologies, the GHG emissions resulted from non-energy industrial activities for iron and steel production sector are $\mathrm{CO} 2$ and $\mathrm{CH} 4$ [7].

GHG emissions in non-energy sectors were calculated using models based on spreadsheets, considering the activity data and production structure of sub-sectors. The emission factors used are specific for the sector (determined by analysing data from previous years), according to the IPCC guidelines. Assumptions specific to sub-sectors were considered.

Emissions projections could be considered as inventories for the future emissions in which the historical data are replaced by a number of assumptions and interpretations. [8]

To estimate emissions, the following formula was used:

$E_{g}(t)=\sum_{i=1}^{n} \sum_{j=1}^{m} \sum_{k=1}^{p} A_{j}(t-1) \cdot p_{k} \cdot\left(1+r_{j}(t)\right) \cdot E F_{g, k}(t)$

where $\operatorname{Eg}(\mathrm{t})$ - emissions projected for the greenhouse gas $\mathrm{g}$ in year $(\mathrm{t})$;

$\mathrm{i}$ - activity sector, which is a source of GHG emissions;

$\mathrm{j}$ - activity sub-sector, which is a source of GHG emissions;

$\mathrm{k}$ - product or material used for whose manufacture or from whose use GHG emissions result;

pk - share of the product/quantity of material used in the activity data of the sub-sector;

rj (t) - growth or decrease factor of the activity data at the activity sub-sector level;

EFg, k (t) - Emission factor for the greenhouse gas $\mathrm{g}$ for the product or material used, in the year t.

\section{Results and discussions}

At national level, in terms of the weight of steel producing processes, in 2001, the share of BOF steel was $72.2 \%$, steel produced in EAF was $33.8 \%$, the rest $(3.2 \%)$ being produced by the $\mathrm{OH}$ process.

In 2011 the share of BOF steel was $48.7 \%$ and EAF steel share $51.3 \% .2011$ is the first year that production of EAF was greater than the BOF steel. This trend was maintained in 2012 (50.4\% EAF steel vs. 49.6\% BOF steel). However, from 2013, due to the insolvency of the group Mechel, national production of EAF steel has decreased and consequently the share of this steel type (38\% in 2013). 2015 production structure by types of flows was: $59.7 \%$ BOF steel and 40.3\%EAF steel.

The economic crisis has seriously affected the steel production in Romania, who decreased by about 4 5\% in 2009, compared to 2008 and around $55 \%$ compared to 2007. The year 2010 marked an increase in the amount of steel produced (with 37\% higher than previous year) to a value of 3,734 kt, but still with $27 \%$ lower than in 2008. By 2011, the steel production was maintained at a value close to the 2010 production (3,813 kt), and in 2012 it dropped again, to a value of $3,452 \mathrm{kt}$. In terms of production values in the years 2013 and 2014, they were about 3,200 kt, and in 2015 the recorded a value is of $3,480 \mathrm{kt}$.

It should also be noted that over $99 \%$ of the steel produced in Romania is carried out in industrial facilities, covered and governed by the EU-ETS. Given the current economic status, one considers the following assumptions for the 
GHG emissions projection:

- In the short term, a reduce capacity using of some EAF steel production units (i.e. Mechel Group);

- In the medium-term, the opening of an 800 $\mathrm{kt} /$ year production (500 kt in the first stage and another $300 \mathrm{kt}$ in the second stage) facility in Oltenita, which will produce EAF steel.

Taking into account the evolution of national and international market request, for GHG emissions estimations will be used the following activity data, under the assumption that in the 2035 will be reached around $80 \%$ of the total production capacity (see Table 2).

Table 2. Total steel projection for Romania for the period $2020 \div 2035$

\begin{tabular}{lllll} 
Product & 2020 & 2025 & 2030 & 2035 \\
\hline $\begin{array}{l}\text { Total steel } \\
\text { production, }\end{array}$ & 4000 & 5000 & 6000 & 8000 \\
kt
\end{tabular}

For the $\mathrm{CO}_{2}$ emissions' projections, the following assumptions for emission factors are considered:

- for the WOM scenario will be used the values shown in the table below for each type of steel and which represent the higher EF value from the past 5 years;

- for the WM and WAM scenarios will be take into account the effect of the application of Directive 2010/75/EU. Thus, the EFs for each type of steel will decrease in the period 20162020 up to the values presented in the table below (95\% of the average of 2013-2015 EFs for BOF steel and $95 \%$ of the average of the 20112015 EFs for EAF steel), and will be kept constant until 2035.

Table 3. The EFs values used in CO2 emissions projections for Iron and Steel Production

\begin{tabular}{lll}
\multirow{2}{*}{ Product } & \multicolumn{2}{l}{$\mathrm{EF}, \mathrm{t} \mathrm{CO}_{2} / \mathrm{t}$ steel } \\
& WOM & WM,WAM \\
\hline BOF steel & 1.743 & 1,517 \\
EAF steel & 0.018 & 0.010 \\
\hline
\end{tabular}

The figure 1 shows the projected evolution of $\mathrm{CO}_{2}$ emissions from Iron and steel production, for the period 2017-2035, under the three scenarios considered.

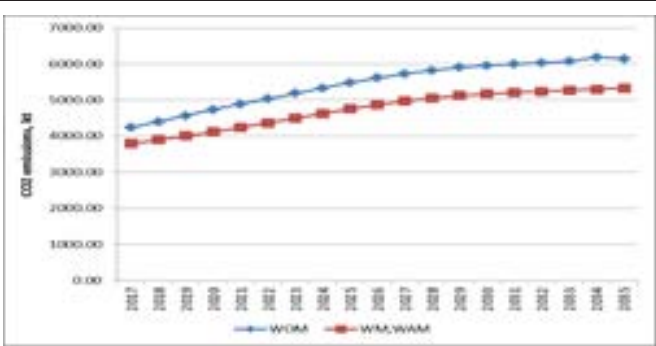

Figure 1. The $\mathrm{CO}_{2}$ emissions projection from Iron and steel production, in the period 20172035

For the $\mathrm{CH} 4$ emissions projections from the sinter production, the following assumptions will be considered:

- for the WOM scenario the default IPCC 2006 $\mathrm{EF}$ will be used, as this value is also used in the national GHG inventory. For the activity data projection, a conversion factor of $1.196 \mathrm{t}$ sinter/t BOF steel, representing the value of 2015, will be used. Both values are considered to remain constant throughout the period 2017-2035.

- for the WM and WAM scenarios, the effects of the application of Directive 2010/75/EU will be take into account. Thus, the conversion factor of sinter in BOF steel will decrease in the period 2016-2020 up to a value of $0.943 \mathrm{t}$ sinter/t BOF steel (representing $95 \%$ of the lowest value in the period 2011-2015), and will remain constant until 2035.

The figure 2 shows the projected evolution of CH4 emissions from Iron and steel production, for the period 2016-2035, for the three scenarios considered.

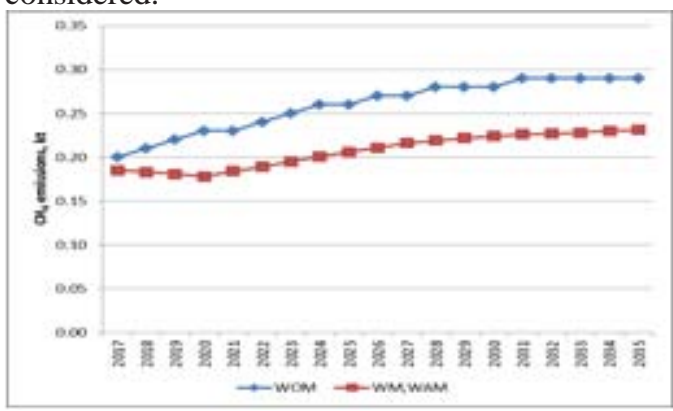

Figure 2. The $\mathrm{CH} 4$ emissions projection from Iron and steel production, in the period 20172035

Regarding the N2O, HFC, PFC, SF6, NF3 emissions, there are no relevant data as result of the iron and steel process. 


\section{Conclusions}

At the national level the iron and steel industry is an important contributor to the GHG emissions, thus development of the GHG projection became a very important in the context of actual legislative framework.

The analysis of existing technology, taking into account the effects of the legislative requirements show that for Romanian iron and steel sector is possible to reach further GHG emissions reduction. The GHG emission projections are based on assumptions about macroeconomic indicators with high uncertainty in the forecast horizon until 2035, due to the economic crisis at national and global level, and the lack of updated strategies by 2035 on industry, agriculture, transport etc. Thus, economic development is a dominant factor affecting the forecast results. Given the fact that the iron and steel sector is one of the branches included in the EU ETS, it has become very important for these industrial plants to use highprecision assessment and forecasting models for $\mathrm{CO}_{2}$ emissions.

\section{Acknowledgment}

The paper is part of the Ph.D. program of eng. Mircea Iulia as Ph.D - student at the Politehnica University of Timisoara.

\section{References}

[1] ***, Mapping Carbon Pricing Initiatives, Developments and Prospects, Ecofys, Washington DC, May 2013, https://www.thepmr.org/content/mappingcarbon-pricing-initiatives-developments-andprospects, accessed May 2017.

[2] O. Edenhofer, R. Pichs-Madruga, Y. Sokona, J. C. Minx, E. Farahani, S. Kadner, K. Seyboth, A. Adler, I. Baum, S. Brunner, P. Eickemeier, B. Kriemann, J. Savolainen, S. Schlömer, C. von Stechow, T. Zwickel, "Climate Change 2014. Mitigation of Climate Change", Working Group III Contribution to the Fifth Assessment Report of the Intergovernmental Panel on Climate Change [3] Best Available Techniques (BAT) Reference Document for Iron and Steel Production, Industrial Emissions Directive 2010/75/EU (Integrated Pollution Prevention and Control), European Commission Institute for Prospective
Technological

Studies,

2012,

http://eippcb.jrc.ec.europa.eu/, accessed May 2017.

[4] Ivan R; Falup O; Mircea I, Ionel I, Vasilescu MD, „Romanian Projections for Certain Atmospheric Pollutants by 2030, as a Result of Implementation the Environmental Legislation", Revista de chimie, Volume 66, Issue 2, Pages 247-250, 2015

[5] Balanescu M., Melinte I., Dobrescu M., Darie G., "Models and tools for the $\mathrm{CO} 2$ emissions assessment and forecast in iron and steel sector", Proceedings of the 2nd IASME / WSEAS International Conference on Energy \& Environment

[6] ***, Steel Statistical Yearbook, World Steel Association, World Steel Committee on Economic Studies-Brussels, 2015, https://www.worldsteel.org/statistics/statisticsarchive/yearbook-archive.html

[7] ***, Best Available Techniques (BAT) Reference Document for Iron and Steel Production, Industrial Emissions Directive 2010/75/EU (Integrated Pollution Prevention and Control), European Commission Institute for Prospective Technological Studies, 2012, http://eippcb.jrc.ec.europa.eu/, accessed May 2017.

[8] Nielsen O-K,. Winther M, Nielsen M., Mikkelsen M. H., .Albrektsen, S. Gyldenkærne, Plejdrup M.,. Hoffmann L, Thomsen M., Hjelgaard K., Fauser P., "Projection of Greenhouse Gas Emissions 2010 to 2030", NERI Technical Report no. 841, National Environmental Research Institute, 2011 